Author Final Copy of Cox, N. (2017) 'Enacting disability policy through unseen support: the everyday use of disability classifications by university administrators' which was accepted for publication by the Journal of Education Policy on 03 Mar 2017. Deposited in concordance with sherpa.ac.uk/romeo/search.php?issn=0268$\underline{0939}$ guidelines. Publisher's final version is available at: $\underline{\text { http://dx.doi.org/10.1080/02680939.2017.1303750 }}$

\title{
Enacting disability policy through unseen support: the everyday use of disability classifications by university administrators
}

Journal of Education Policy

\section{Dr Nigel Cox}

Senior Lecturer, Faculty of Health, Psychology \& Social Care, Manchester Metropolitan University, Brooks Building, 53 Bonsall Street, Manchester M15 6GX

$$
\begin{array}{ll}
\text { E: } & \text { n.cox@mmu.ac.uk } \\
\text { T: } & +44(0) 1612472235 \\
\text { ORCID } & 0000-0002-4159-9449
\end{array}
$$

\section{Word count}

9030 less references

\begin{abstract}
In the United Kingdom (UK), Higher Education Institutions share with other educational providers the duty to provide reasonable adjustments for students who disclose disabilities. The role of academic administrators in the operationalisation of legislation-driven policy related to disability within the university context is overlooked within empirical and theoretical literature, and explicit recognition of the administrative role is often reduced to descriptions of bureaucratic processes and training requirements. This paper makes an empirical and theoretical contribution by explicitly recognising the unique operational and personal practices of educational administrators as they undertake disability-related work. Drawing upon a larger ethnographic study that employed observation, in-depth qualitative interviews and discourse analysis, the findings start to reveal the subtle interactional practices that administrators undertake during their everyday work with people disclosing of a disability; these revelations offer indicators for future staff training and development.
\end{abstract}

\section{Keywords}

higher education; administration; students; disability; equality; diversity

\section{Author biography}

Dr Nigel Cox is a registered nurse and senior lecturer at Manchester Metropolitan University. He holds a doctorate in Sociology and Fellowship of the Royal Anthropological Institute. His research focuses on the social and cultural experience of health and wellbeing, and practices public involvement as Executive Chair of the NW People in Research forum. Lately, he has delivered a voluntary sector evaluation for the UK Cabinet Office in partnership with Greater Manchester Youth Network, supplied a scoping review for Nuffield Health, co-produced fieldwork with both substance-use recovery and care-leaver communities, and published papers about Global Mental Health and barriers faced by GLBT people. 
Author Final Copy of Cox, N. (2017) 'Enacting disability policy through unseen support: the everyday use of disability classifications by university administrators' which was accepted for publication by the Journal of Education Policy on 03 Mar 2017. Deposited in concordance with sherpa.ac.uk/romeo/search.php?issn=0268$\underline{0939}$ guidelines. Publisher's final version is available at: $\underline{\text { http://dx.doi.org/10.1080/02680939.2017.1303750 }}$

\section{Introduction}

This paper explores an under-examined aspect of higher education (HE) labour: the personal and interpersonal agency exercised by educational administrators as they undertake activities that, directly or indirectly, serve to influence the experience of students with disabilities in the university setting; herein, these activities are described as 'disability-related work'. Drawing upon a larger ethnographic study, the data and analysis reveal the subtle and habitually overlooked interpersonal practices that administrators undertake in their everyday work with regard to disability; these revelations offer indicators for future training and education.

Herein, administrators are identified as those people who support the academic mission of the university through their facilitation of policy and process (e.g., assessment boards), the pastoral support of students (e.g., advisory services), or via their delivery of the wider professional functions of the university (e.g., human resources) (Selwyn, Henderson, and Chao 2016; Whitchurch 2006, 2008). Reflecting broader changes within the higher education sector (Szekeres 2011), the role of university administrators within the United Kingdom (UK) is evolving, and the concurrent revision of UK equalities legislation has served to transform those aspects of their role which relate to the needs of people with disabilities; these changes provide the context for this study.

\subsection{Research question}

This study addresses the research question: How do administrators construct and practice disability classifications in their everyday work? There is a paucity of research that represents the individual experience of university administrators. Beyond the university context, studies that incorporate junior or mid-level administrators address a wide range of contexts, for instance, administrator-teacher relationships and change management (Elstad 2008; Honig 2009); office spaces and culture (McElroy and Morrow 2010), administrators, race, ethnicity and gender (Thurlow-Brenner 2009) and, most recently, the nexus of administrative work and organisational data (Selwyn, Henderson, and Chao 2016). Nonetheless, an argument can be made that higher education administrators have been persistently under-represented within scholarly enquiry (Selwyn, Henderson, and Chao 2016; Dobson 2009; Zimmerman and Allen 2009; Szekeres 2004). The role of the administrator in higher education is evolving and, for some, their role now encompasses critical work relating to the student experience of 
Author Final Copy of Cox, N. (2017) 'Enacting disability policy through unseen support: the everyday use of disability classifications by university administrators' which was accepted for publication by the Journal of Education Policy on 03 Mar 2017. Deposited in concordance with sherpa.ac.uk/romeo/search.php?issn=0268$\underline{0939}$ guidelines. Publisher's final version is available at: $\underline{\text { http://dx.doi.org/10.1080/02680939.2017.1303750 }}$

disability. Hence, enquiry into how administrators participate in the practice of disabilityrelated work is important for university staff and students alike, and deserving of study.

\subsection{Background}

This research interconnects four distinct contexts. One context is the over-arching legislative context for disability-related administrative work within UK higher education, the Equality Act 2010 (United Kingdom 2010), and its evolution from antecedent laws to its present-day manifestation. Development of a higher education 'marketplace' in the UK provides another context, inviting reappraisal of administrative roles as these are adapted to the emerging imperatives of consumerism and quality assurance. A third context is provided by the evolving constellation of research positions collectively (albeit tentatively) characterised as 'critical disability studies', a corpus to which this research makes a contribution. A fourth context, institutional ethnography (Smith 2006), provides this study with a methodological substrate that imbricates the governance of people, places and their organisational practices.

\subsubsection{Legislative context in the United Kingdom}

One transformation affecting disability-related administrative work in higher education is the evolving legislative context in the UK. Legislation extant during the preliminary fieldwork for this study were the Disability Discrimination Act and the Special Educational Needs and Disability Act (United Kingdom 1995, 2001, 2005). Whilst fieldwork was being conducted, revised legislation (the Equality Act 2010) (United Kingdom 2010) was introduced. This combined and harmonised existing anti-discrimination legislation, explicitly naming nine protected characteristics (including disability), and incorporated a Public Sector Equality Duty which outlined responsibilities for Public Sector organisations, including providers of higher education (Hepple 2014).

The Disability Discrimination Act (United Kingdom 2005) integrated an additional element, styled as a Disability Equality Duty (DED), and this was incorporated (in an extended form) within the Equality Act. This duty requires public sector organisations and authorities to gauge and monitor the impact of their policies and practices with respect to people with disabilities, to eliminate disability discrimination, improve opportunities for people with disabilities and promote 'positive attitudes' towards people with disabilities (United Kingdom 2005). Organisations, including universities, were also required to publish a Disability 
Author Final Copy of Cox, N. (2017) 'Enacting disability policy through unseen support: the everyday use of disability classifications by university administrators' which was accepted for publication by the Journal of Education Policy on 03 Mar 2017. Deposited in concordance with sherpa.ac.uk/romeo/search.php?issn=0268$\underline{0939}$ guidelines. Publisher's final version is available at: $\underline{\text { http://dx.doi.org/10.1080/02680939.2017.1303750 }}$

Equality Scheme (DES) in order to demonstrate how they planned to fulfil the requirements of the disability discrimination legislation.

Briefly, the legislation requires universities to provide reasonable adjustments students who disclose a disability. For instance, a student may require additional equipment, an adaptation to standard provisions, or bespoke pastoral support, in order to enable their full participation. Universities must also provide anticipatory adjustments, in advance of a specific application from a person with a disability, in order to remove barriers that might discourage and deter a person from making an application to study. Many of these requirements demand an administrative intervention: for instance, during the admission process, administrators play an instrumental role in providing an environment for the consensual disclosure of a disability by a student; simultaneously, this encounter also provides administrators with an opportunity to gather data to inform institutional audit of disability/equality monitoring processes.

\subsubsection{The student as consumer: evolving opportunities for administrative practice}

Changes to higher education funding in the UK has also been transformative. Since 2012, partly in response to the Independent Review of Higher Education Funding and Student Finance (Browne et al 2010), a majority of full-time university students in England (Scotland, Northern Ireland and Wales have separate provisions) pay tuition fees through a system of graduate contributions (Browne et al 2010). This means that university staff are increasingly obliged to meet the expectations of fee-paying students (Szekeres 2004, 2006, 2011); this challenges orthodox notions of the student-university relationship, with consequential impacts upon the role of administrative workers.

An increased emphasis upon the student experience of higher education is intimately bonded to the evolution of the student as 'consumer', a "discourse of 'quality"' (Dobson 2009, 10) and adoption of business methodologies aligned with these positions. In the context of a competitive educational marketplace, the quality of student services is understood to offer an important marketing advantage: as students increasingly identify themselves as 'customers', their perception is echoed in how they appraise the service they receive. For instance, in the UK, the National Student Survey (NSS) plays a dominant role in the shaping of University policy and practice at local and national levels.

The evolution in the relationship between students-as-consumers and higher education 
Author Final Copy of Cox, N. (2017) 'Enacting disability policy through unseen support: the everyday use of disability classifications by university administrators' which was accepted for publication by the Journal of Education Policy on 03 Mar 2017. Deposited in concordance with sherpa.ac.uk/romeo/search.php?issn=0268$\underline{0939}$ guidelines. Publisher's final version is available at: $\underline{\text { http://dx.doi.org/10.1080/02680939.2017.1303750 }}$

providers is of significance to administrative workers because, in contrast to teaching and research, the co-requisites of academic activity (e.g. disability support services) are arguably more amenable to the imposition of quality management processes and configuration of services as a 'product' (Sharrock 2000). However, students are atypical customers and, whereas a customer-retailer relationship is transactional, the relationship between student and higher education provider requires a complex exchange of agency, effort and resources.

This revised relationship between universities and their fee-paying students has led to a transformation in administrative work. Traditionally viewed as subordinate to academic staff, administrators are increasingly required to offer enhanced and specialised services, as universities strive to position themselves within a higher education marketplace. However, there exist for administrators a set of tensions, namely the conflict between delivering an institutionally imposed set of standards and the agency required to engage with a diverse range of students who may articulate a complex set of expectations. In a context where the student is both a 'customer' and learner, administrators necessarily act as agents, mediating between the consumerist principles of the higher education 'marketplace' and legal duties (here, in relation to disability). This requires of administrators a revised set of knowledge, skills and affective characteristics (Whitchurch 2008), and disability-related work is one of area where administrators are creating new opportunities for their practice.

\subsubsection{Theoretical contexts for disability research}

Described as the "academic site to watch" (Shildrick 2012, 30), critical disability studies (CDS) is characterised by its philosophical, transdisciplinary and rhetorical agility, and its commitment to critique and problematization of its own and other positions. Although it may be concerned with 'the discursive', CDS does not reject materialist ideas about disability (Goodley 2016) although it may destabilise them (Shildrick 2012). As such, although CDS respects orthodox positions, such as the individual and social models (see Barnes and Mercer 2010), CDS views neither as critical antecedents of political or material 'truths' about disability, instead viewing both as participants in a broader epistemic and material 'conversation' about disability.

CDS is multi-sited and transdisciplinary, involving of people or institutions who might not identify themselves (or be identified by others) explicitly in relation to disability: in this 
Author Final Copy of Cox, N. (2017) 'Enacting disability policy through unseen support: the everyday use of disability classifications by university administrators' which was accepted for publication by the Journal of Education Policy on 03 Mar 2017. Deposited in concordance with sherpa.ac.uk/romeo/search.php?issn=0268$\underline{0939}$ guidelines. Publisher's final version is available at: $\underline{\text { http://dx.doi.org/10.1080/02680939.2017.1303750 }}$

paper, it is educational administrators and higher education labour that provide a context for enquiry. A problematization of normativity, agency and the nature of disabled/non-disabled identities forms a crucial aspect of the character of CDS; this, combined with a sustained and contemporary critique of stable, fixed conceptions of disability (for instance, Kerschbaum 2014) attaches it to a poststructuralist position. Herein, CDS describes a nexus of individual, social and institutional concerns, within which agents persistently question their work practices, normalcy, and the implementation of university policy.

\subsubsection{Methodological context for disability policy enquiry}

Transformational change within higher education and, concurrently, progression of disability representation in law and policy, exposes administrators to matters that are bureaucratic, affective and politicised. To describe these circumstances, a methodological approach is required that is sensitive to the interaction between educational administrators and disabilityrelated policy enactment. Moreover, consistent with a critical disability standpoint, an approach that is not overly dogmatic in its interpretative standpoint is also required. Institutional ethnography provides one such methodology.

Originated by sociologist Dorothy Smith, institutional ethnography is a coalition of approaches focused upon the institutional practices of people, and the 'relations of ruling' (Smith 2006) that interconnect, govern and transform (for better or worse) their experience. The term 'institutional' in this context does not refer to a singular organisation, but rather describes the "intersecting work processes" (De Vault and McCoy 2006, 17) that connect people and their practice. This study interrogates the 'relations of ruling' (Smith 2006) that bind the work of university administrators with the policies they are required to enact. A critical disability standpoint necessarily problematizes these 'relations of ruling', showing how they may be implicated in the creation and recognition, or the rejection and exclusion, of particular identity positions (for instance, 'a person with a disability').

\section{Method}

This paper extracts data, analysis and findings from a larger ethnographic study of the disability-related practices of university administrators conducted within an urban, multicampus university in the United Kingdom. Data reported in this paper were obtained through in-depth, qualitative interviews undertaken with junior and mid-level administration staff. 
Author Final Copy of Cox, N. (2017) 'Enacting disability policy through unseen support: the everyday use of disability classifications by university administrators' which was accepted for publication by the Journal of Education Policy on 03 Mar 2017. Deposited in concordance with sherpa.ac.uk/romeo/search.php?issn=0268$\underline{0939}$ guidelines. Publisher's final version is available at: $\underline{\mathrm{http}} \mathrm{://dx}$.doi.org/10.1080/02680939.2017.1303750

Field-notes were recorded during observational visits to workplace environments and used to document how different kinds of administrative work were performed in practice (e.g. enrolment or employment advice). Field notes also supported transcription of interviews: for instance, when participants described a process using both spoken recollection and physical props (e.g. a computer display), then field notes permitted contextualisation of interview data.

Organisational documents were also gathered; these included standardised forms for completion by administrators or students (e.g. a Disability Disclosure Form), information leaflets for students and staff, and formal procedural guidelines. Analysis of these contributed to the wider study and are not described herein; however, close examination of these texts informed the interview process and the subsequent interpretation of data. The over-arching fieldwork was conducted by a sole researcher, an educator and anthropologist, and was aligned over an initial five year period (2008-12), with subsequent analysis, in order to follow closely the enactment and impact of revised UK legislation (the Equality Act 2010) upon administrative process and practice in the HE setting.

\subsection{Access and recruitment}

The over-arching research involved twelve individuals, seven of whom are referred to in this paper (Table 1). Participants were selected purposefully to typify a range of junior, intermediate and senior-level administrative roles. None of the participants were employed in roles that were exclusively disability-centred, and no participant disclosed additional vocational or professional proficiency in disability-centred work. All respondents engaged in direct student contact, although junior-grade administrators undertook this more habitually than their senior colleagues. Unconditional access was granted via a gatekeeper, a senior administrator. None of those invited to participate in an interview declined to participate.

\section{[Table 1 to insert near here]}

\subsection{Ethical considerations}

All participants were provided with written and verbal information about the study by the researcher. Participants were then asked to sign an informed consent form. To protect anonymity and minimise the risk of retrospective identification following the reporting of findings, respondents were accorded pseudonyms and specific details of their roles were 
Author Final Copy of Cox, N. (2017) 'Enacting disability policy through unseen support: the everyday use of disability classifications by university administrators' which was accepted for publication by the Journal of Education Policy on 03 Mar 2017. Deposited in concordance with sherpa.ac.uk/romeo/search.php?issn=0268$\underline{0939}$ guidelines. Publisher's final version is available at: $\underline{\text { http://dx.doi.org/10.1080/02680939.2017.1303750 }}$

disguised. Digital audio-recordings of interviews and their transcribed text were stored upon a password-protected computer. The research was approved by the host university's local research ethics committee.

\subsection{Data collection}

Pre-arranged fieldwork (e.g. visits to offices) involved direct observation of administration activities, usually lasting less than one hour, followed by individual, in-depth, looselystructured interviews (Wengraf 2001). These lasted between one and two hours, and were conducted in a location where privacy could be sustained. An interview schedule was devised and used to strengthen consistency, and all interviews were recorded and transcribed by the researcher. Participants were offered an opportunity to review the accuracy of their transcript, although none elected to do so.

During interviews, respondents were asked to provide examples of how they might use disability-related language in their everyday administrative work. Such an approach is fundamental to ethnographic interviewing (see Spradley 1979) because it aids interpretation in situations where local (emic) understanding of the relationship between 'words' and associated practices is sought. For example, respondents were not asked to explicitly 'define disability' or 'describe the process'; rather, they were asked to 'provide examples' of situations when they had initiated an administrative procedure, or had, conversely, adapted a process to suit the preferred lexicon of the student with whom they were corresponding.

This approach was influenced by the principles of institutional ethnography (Smith 2006) whereby, given the standardisation of disability-related processes across the organisation, interviews offered an opportunity to learn both about the "extended relational chain" (De Vault and McCoy 2006, 23) that administrators are obliged to follow, whilst also eliciting evidence of the (unscripted) personal agency that they brought to their prescribed roles. Data were gathered which described both 'formal', institutionally-prescribed processes, and the personal agency that administrators 'informally' adapted into institutional processes.

\subsection{Data analysis}

Transcribed interview data, field-note data and ancillary documents were loaded into qualitative data analysis software (QSR Nvivo 9). All texts were read on multiple occasions 
Author Final Copy of Cox, N. (2017) 'Enacting disability policy through unseen support: the everyday use of disability classifications by university administrators' which was accepted for publication by the Journal of Education Policy on 03 Mar 2017. Deposited in concordance with sherpa.ac.uk/romeo/search.php?issn=0268$\underline{0939}$ guidelines. Publisher's final version is available at: $\underline{\text { http://dx.doi.org/10.1080/02680939.2017.1303750 }}$

both during and after the extended period of ethnographic research. Throughout this process, efforts were made to avoid linguistic reductionism (Alvesson and Sköldberg 2009); to accomplish this, a Foucauldian standpoint on discourse was adopted (Foucault 1997; Mills 2004): this meant that rather than treating the interview data as detached 'words' and 'sentences' for close linguistic analysis, data were extracted iteratively (Wengraf 2001) and interpreted as complex 'discursive statements' across the dataset. These data were coded using descriptive code-names (e.g. "categorising disabilities") to assist analysis.

Consistent with critical disability perspectives (above), this approach refuted analytic approaches organised around orthodox and (potentially) marginalising notions of disability or difference (Kerschbaum 2014). Instead, drawing upon the theory and practice of institutional ethnography (Smith 2006), analysis focused upon how administrators explained their use of organisational texts (for instance, paperwork, policies and protocols) and described the 'occasions for action' (Pence 2001) for the accomplishment of administrative work (for instance, 'disability disclosure' or 'form-filling'). An over-arching category constructed during analysis concerned the normalization and attempted 'classification' of disability by administrators; in this paper, this over-arching category is resolved into three sub-analyses: how disability is rendered recognisable through classification, how less regular classifications are subjected to classification attempts, and how attempts to classify might be challenged.

\section{Findings}

The findings represent a range of administrative performances, ranging from the highly disciplined and regularised 'administrative encounter' to those less which were indeterminable in effect. First, how disability is rendered into a recognisable classification through administrative intervention is described then revealed as both an agential and ideological performance, and the stability and tolerability of certain classifications (for instance, dyslexia) to the administrative regime are explored. Second, and in contrast, less regular classifications are considered (chiefly, issues pertaining to mental-wellbeing), and the administrative threat of failed or repudiated disability classifications is described. Finally, the spectre of resistance to administrative intervention is described and explored. Discussion and theoretical exposition are elaborated in the subsequent discussion. 
Author Final Copy of Cox, N. (2017) 'Enacting disability policy through unseen support: the everyday use of disability classifications by university administrators' which was accepted for publication by the Journal of Education Policy on 03 Mar 2017. Deposited in concordance with sherpa.ac.uk/romeo/search.php?issn=0268$\underline{0939}$ guidelines. Publisher's final version is available at: $\underline{\text { http://dx.doi.org/10.1080/02680939.2017.1303750 }}$

\subsection{Recognisable classifications}

Dyslexia, when classified as a Specific Learning Difficulty (British Dyslexia Association n.d.), is reported to be the disability most commonly disclosed by students within UK higher education, and students disclosing a mental health condition are reported to be those who feel least well served (Higher Education Funding Council for England 2016). These national data are consistent with the voiced experience of participants in this study: during fieldwork, although some participants named a range of disability classifications (for instance, sensory or physical disabilities), a majority named dyslexia and mental health persistently. Interviewees frequently differentiated the two groupings, inviting an analytical exploration of how each classification was implicated within administrative work.

For many students, their first encounter with a member of the administrative staff is during the formal enrolment process. During enrolment, one administrative role is to greet students, issue them with a questionnaire comprising a set of pre-determined questions, and then enter this personal information into the University's centralised computer database. The prescribed administrative process then requires the administrator to verify the self-ascribed disability status information provided by the student. It then becomes the administrator's responsibility to record this information in a format suitable for entry into the database. Whilst it is not an administrator's role to counsel students about how they should describe their disability, this administrator explains how this process nonetheless requires his facilitation:

S We have to ask students when they enrol whether they have a disability

I How do you do that?

S When they fill in the enrolment form, there's a tiny little box 'yes or no', 'do you have a disability?'

I So, you say, 'have you got a disability?'

S Well, no. We give them the form, and then they fill it in.

I Do they ask you about that [part of the form]?

S [laughs] occasionally!

I What sort of questions do they ask?

S They might have something that they're not sure is a disability or not 
Author Final Copy of Cox, N. (2017) 'Enacting disability policy through unseen support: the everyday use of disability classifications by university administrators' which was accepted for publication by the Journal of Education Policy on 03 Mar 2017. Deposited in concordance with sherpa.ac.uk/romeo/search.php?issn=0268$\underline{0939}$ guidelines. Publisher's final version is available at: $\underline{\text { http://dx.doi.org/10.1080/02680939.2017.1303750 }}$

I Can you give me an example?

S Dyslexia

I So they might say, 'I have dyslexia, is that a disability?' What would you say?

S [laughs] Well, I would pull out my form that says [lists] what 'are' disabilities. If the student ticks 'no', we just ignore it. If the student ticks 'yes', we have to give them a separate form which says...well, it has about six tick boxes and a list of disabilities, 'please tick the one that applies to you' [...] That's my understanding of it, to prevent discrimination.

[S: junior administrator; I: interviewer, abridged interview extract]

These data show how a student's disclosure of disability is first negotiated and authenticated with the administrator prior to being assigned a pedagogic-administrative classification that can be accepted by the database. The naming of dyslexia and its insertion into the apparatus of administration function to authorise it as a legitimate disability category and, indeed, many commented on the frequency in which they encountered dyslexia in their everyday work:

$\mathrm{K}$ It surprises me the number of dyslexic people who come through [this office], I mean I've had about five hundred since April [eight months previously] which is a pretty big number when you consider $[\ldots]$ These are changing times nowadays, more people must know somebody who has something like dyslexia...

[K: junior administrator, abridged]

For some administrators, a knowledge of how to provide reasonable adjustments in response to a disability disclosure is an important aspect of their role. When supporting the organisation of timed examinations, this administrator rarely finds it necessary to communicate directly with individual students. Rather, she makes use of the disability information already recorded about individual students, here circulated in the form of a personal learning plan for students disclosing a disability. Therefore, her interaction is with the disability classification recorded by the university, not with the student directly, and her role requires knowledge of the reasonable adjustments that these entail:

I [so] the majority disability that you are working with is dyslexia?

J Yeh [yes]

I Are you dealing directly face-to-face with students? 
Author Final Copy of Cox, N. (2017) 'Enacting disability policy through unseen support: the everyday use of disability classifications by university administrators' which was accepted for publication by the Journal of Education Policy on 03 Mar 2017. Deposited in concordance with sherpa.ac.uk/romeo/search.php?issn=0268$\underline{0939}$ guidelines. Publisher's final version is available at: $\underline{\text { http://dx.doi.org/10.1080/02680939.2017.1303750 }}$

J Well, I suppose it's more 'about' them [...] it's less 'face to face'

I What do you do with them that's different?

J They get separate...they get extra time for their assessments, so they have a different hand-in date, they get extra time in exams, and they're usually in a different room, and they might get rest breaks, they might have to have a reader...

I How do you know what to do?

J They'll have a personal learning plan made up by learner support, so they've had an assessment, and then we get just this assessment through

I And you have access to that [learning plan]?

J Yep [yes]

I And what are your thoughts when going through it?

J Err [pause], 'What do I need to do?' [laughs, gestures feigned confusion]

I How do you get the information you need from the [learning plan]?

$\mathrm{J}$ Err, I just look at ...there's a heading [in the text] for assessments or examinations [...] I'll look at that [to see if it says] for extra time...students normally have twenty-five percent [extra time], it might say 'provide a computer', 'provide a scribe', 'provide a reader'

[J: junior administrator, abridged]

This interaction reveals a processing interchange (Pence 2001; Smith 2006) through which administrative duties are accomplished. The fixed form of the personal learning plan deprives the student and administrator of agency and, whilst the development of the plan is ostensibly 'personalised' (in that it is generated for an individual student), its content is mostly predetermined. Therefore, the administrative task is accomplished through the imbrication of impairment-based notions of normalcy, administrative-academic resources (computer, scribe, readers) and the legal duty to make anticipatory adjustments.

Critically, the normalization of the person with a disability as a pathological 'case' combines with the rectifying interventions of the administrator to perform ideological work (Pence 2001). This work is ideological inasmuch as it is the 'natural' response that workers in this context 'expect' to happen. Denied decisional agency, they act ritualistically (Douglas 2002) to protect administrative practice, guarding against violations of the law and helping to 
Author Final Copy of Cox, N. (2017) 'Enacting disability policy through unseen support: the everyday use of disability classifications by university administrators' which was accepted for publication by the Journal of Education Policy on 03 Mar 2017. Deposited in concordance with sherpa.ac.uk/romeo/search.php?issn=0268$\underline{0939}$ guidelines. Publisher's final version is available at: $\underline{\text { http://dx.doi.org/10.1080/02680939.2017.1303750 }}$

sustain and propagate impairment-based and fixed notions of disability. Moreover, this has potentially marginalising implications for students disclosing disabilities: the fixity and bureaucratic durability of the personal learning plan risks stripping students of their opportunity to broker, at the point of accommodation, the means by which their inclusion in higher education might be sustained and strengthened.

Whilst none of the respondents rejected entirely the administrative imperative to name, classify and document a student's disability, some respondents invited discussion about the precision of disability classifications. Administrators with longer time in service were more likely to explain their knowledge of disability in terms of their prior experiences; although their descriptions elaborate their desire to meet the needs of individual students, such descriptions often remained bonded to administrative process:

M Dyslexia is not black and white and there are various degrees of dyslexia and there are different resources that different students need. [My knowledge has] come from looking at information about dyslexia, and just getting a broader knowledge 'cos I like to be in a position to say or to know or to be able to help

$[\ldots]$

Some staff [are] now in key [disability-related] roles. And I think that it's staff in key roles that have the knowledge ... If the student disclosed that they have dyslexia, then we would find out, they would provide their ... psychological profile, their assessment. And that always specifies the kind of support that the student would find helpful... So we would try and find where possible provide that student with the resources to help them [M: office manager, abridged]

Exceptionally, some administrators did express concerns about disability classifications. Whilst at no time during the fieldwork were their comments critical of individuals for whom disability was a personal concern, some administrators did express misgivings about expertled disability classification processes that were sensitive to particular disability classifications, whilst excluding (from additional support) others who might also benefit:

Y Anyone else who is struggling for other reasons, if we can't manage to find a disability label to put on them, it's going to be 'paddle your own canoe' ... and one of the worries that I have [is] that somebody's who's labelled as having mild dyslexia [...] gets 
Author Final Copy of Cox, N. (2017) 'Enacting disability policy through unseen support: the everyday use of disability classifications by university administrators' which was accepted for publication by the Journal of Education Policy on 03 Mar 2017. Deposited in concordance with sherpa.ac.uk/romeo/search.php?issn=0268$\underline{0939}$ guidelines. Publisher's final version is available at: $\underline{\text { http://dx.doi.org/10.1080/02680939.2017.1303750 }}$

exactly the same consideration [and] more or less the same concessions [...] as somebody who's got moderate to severe dyslexia

[Y: senior administrative manager, abridged]

In recognising that there is a formal assessment, this administrator agrees that dyslexia can be recognised and classified, usually by an expert (here, an educational psychologist). However, she does question whom the apparatus of classification serves, and her sense of injustice arises from her view that one classification group (people with dyslexia) is afforded a uniform level of support, irrespective of individual experience, whereas others who might benefit from additional supports are not recognised:

Y My personal view is that you should only [receive a substantive intervention] if you're dyslexic and it's moderate to severe [...] when somebody who is from a lower socio-economic group, no background of being in higher education, no background of knowing how to study [does not receive support]

[Y: senior administrative manager, abridged]

This standpoint entwines, but fails to reconcile, her concerns about the importance and exactness of disability classification with a voiced commitment to social justice. Her exasperation perhaps arises because, whilst she is clearly recognising of the learning needs arising from a diagnosis of dyslexia, she nonetheless expresses concern that dyslexia might be 'over governed' when compared with the needs of other groups not 'captured' by learning support policy. In effect, dyslexia has become a protected, 'cherished classification' in this context (see Douglas 2002), foregrounded for policy attention and intervention, arguably leaving other factors that mediate student success overlooked.

Juxtaposed, the administrative procedure for disclosing, classifying and providing accommodations for dyslexia, and the administrators' recollection of how they accomplish their role, exposes the observing, normalizing and corrective (Foucault 1995) imperative of the administrative process. The administrative system anticipates and demands a 'stable and tolerable' subject (here, a person disclosing a disability) who may be efficiently subjectivised and classified - 'Here is a person with dyslexia' - a person who then is accommodated, by means of 'reasonable adjustments', in a way that does not disrupt the social and pedagogic order of the organisation. This raises further questions about how the administrative regime 
Author Final Copy of Cox, N. (2017) 'Enacting disability policy through unseen support: the everyday use of disability classifications by university administrators' which was accepted for publication by the Journal of Education Policy on 03 Mar 2017. Deposited in concordance with sherpa.ac.uk/romeo/search.php?issn=0268$\underline{0939}$ guidelines. Publisher's final version is available at: $\underline{\text { http://dx.doi.org/10.1080/02680939.2017.1303750 }}$

responds to people who disclose disabilities that are less susceptible to observation, normalization and the providing of 'reasonable adjustments'; this is now explored.

\subsection{Less regular classifications}

Using the 'list of disabilities' prescribed by university policy and systems of work, administrators were able to show a consistent capability in designating disability classifications through skilful interaction with students and organizational systems. In administrative practice, these classifications attain durable, verifiable, 'truthful' status and are sustained and propagated via a nexus of power relations. For instance, the validity of dyslexia is sustained, in part, by its epistemic status as scientific classification (recorded in ICD-10, the 10th revision of the International Statistical Classification of Diseases, World Health Organization [1992]). This classification is emboldened by the imperative for student success: identifying dyslexia 'earlier' rather than 'later' deemed a priority. Moreover, through accumulation of administrators' agency, oft-used classifications sustain legitimacy through repeated exercise and propagation through administrative systems and everyday 'office talk'.

In contrast, respondents' explanations of their administrative response to mental disabilities varied widely and complex modes of classification were in evidence:

A There are the shifting sands about what defines 'mental health'. We all at some point have mental health issues [but] it's the consequences of those mental health issues for, you know, in the context of university, for performance. It's a mental health issue if they're asked to do something and they can't do it.

[A: faculty advisor, disability affairs]

Y Well, the two disabilities which [...] make the University most 'shaky' are mental health and dyslexia and I have to say that in terms of the student resources for supporting students that those [categories] are quite demanding.

[Y: senior administrative manager, abridged]

Another administrator explains how she understood mental disabilities to be 'unstable' when compared to physical disabilities (here, 'wheelchair users'). This administrator's role involves preparing and supporting students for future employment, for instance, during a 
Author Final Copy of Cox, N. (2017) 'Enacting disability policy through unseen support: the everyday use of disability classifications by university administrators' which was accepted for publication by the Journal of Education Policy on 03 Mar 2017. Deposited in concordance with sherpa.ac.uk/romeo/search.php?issn=0268$\underline{0939}$ guidelines. Publisher's final version is available at: $\underline{\text { http://dx.doi.org/10.1080/02680939.2017.1303750 }}$

placement or when seeking employment at the end of a programme of university study:

V There's 'sort-of obvious' barriers, and there's the not-so obvious barriers. There's the complexities in people's lives that become a barrier to them being sustained in employment, you know. The fact that people do get these set-backs, if people's condition isn't one of stability, like you know, the kind of condition that comes and goes, and that is another big problem, because a lot of the time, people don't get DLA [Disability Living Allowance] because it [their disablement] isn't every day [constant, predictable]. And so people who are disabled, there's so much more to prove to an employer.

Employers are really happy with people who are wheelchair users, they think that's fantastic [...] but when it's mental health, or something that's got that instability factor $[\ldots]$ it can be a real problem

[V: Student employment advisor, abridged]

This administrator finds that people afforded a classification of disability relating to a physical impairment ("wheelchair users") appear to be preferred (by potential employers) to those classified in respect of what she describes as "mental health", or "something that's got that instability factor". Here, the wheelchair user is a safe category, ubiquitous as a visual symbols of disablement (Hughes 2004), articulating with legal and architectural requirements in respect of 'access' and, as a metaphor for loss or difference, is inserted frequently into the rhetoric of 'inclusion'. This understanding was voiced by other administrators:

$\mathrm{K}$ [as depicted by] that kind of cloying 'after school special' kind of thing, where it's like "In a very special episode of [a television programme], Natalie's wheelchair-bound cousin shows up", and the kids have to learn how to behave sensibly with someone in a wheelchair, and "Hey, so we're not so different after-all!" [...] And even when I talk to students on the "phone and I say, "this is in regard to your disabled student's allowance", I hope they're not going to be sensitive about me using the word 'disabled' [...] I feel that they're going to think that I think that they're in a wheelchair or [...] they are something that they're not.

[K: junior administrator, abridged]

The hesitant use of the word 'disabled' reveals how this administrator has become implicated in the (re)production of ontologically-negative disability labels - that is, 'disability' described in terms of individual 'losses' or 'deficits' (Campbell 2005). Seemingly conscious of the ways in which (disabling) power is exercised through 
Author Final Copy of Cox, N. (2017) 'Enacting disability policy through unseen support: the everyday use of disability classifications by university administrators' which was accepted for publication by the Journal of Education Policy on 03 Mar 2017. Deposited in concordance with sherpa.ac.uk/romeo/search.php?issn=0268$\underline{0939}$ guidelines. Publisher's final version is available at: $\underline{\text { http://dx.doi.org/10.1080/02680939.2017.1303750 }}$

language, she attempts to minimise the pejorative and injurious force of the words she uses. However, in trying to minimise harm, she then amplifies the 'othering' effect of her language and its presumption of fixity ('something that they're not'). As such, these data show how some administrators might attempt to avoid terminology that might be injurious to a person with a disability. However, these data also show that this is not always successful and, indeed, risks hindering their ongoing conversations.

\subsection{Challenging classifications}

Some administrators are employed in roles that involve securing work placements for students; administrators identify then 'match' students with available work placements. This process sometimes involves invoking reasonable workplace adjustments for students disclosing a disability; if a disability has not been disclosed, then the administrator cannot activate this process. In this interview, the administrator describes a complex set of circumstances in which dialogue with the student had not been continuous.

These data show how students who fall outside the discursive limits of what can be 'named' as a disability risk being labelled as "dangerous" (Douglas 2002, 48), inviting 'explanation' in other ways. Unable to contact their 'first choice' of administrator, located in another office, an altercation arises between a student and the interviewee, an administrator. Her account of the altercation (a series of quarrelsome telephone calls, followed by an unplanned visit to the office by the student) offers insight into the administrative 'framing' of normalcy:

I Have they said at the [other] office that ... they moved him to you?

V Well, no. he moved [himself] here [laughs]

$[\ldots]$

I sent him some information just on voluntary work because the discussion that I'd had with the [placement] provider that he's under was that he needs more proof that he's employable. And, erm, now I know his history, I think he's unemployable, you know, no employer could risk taking him [...] he can't be stable for more than a few days, if that.

V Well I don't understand why he's not just being told at [the other support office] that 'we can't help you any more' [...] I've done what I needed to do, I don't need to keep seeing [him]. [But,] he's phoned up today and spoken to our manager, and the [only] 
Author Final Copy of Cox, N. (2017) 'Enacting disability policy through unseen support: the everyday use of disability classifications by university administrators' which was accepted for publication by the Journal of Education Policy on 03 Mar 2017. Deposited in concordance with sherpa.ac.uk/romeo/search.php?issn=0268$\underline{0939}$ guidelines. Publisher's final version is available at: $\underline{\text { http://dx.doi.org/10.1080/02680939.2017.1303750 }}$

reason for speaking to our manager was because he couldn't get through to the manager at [the other office].

\section{$[\ldots]$}

So this is somebody who's trying to find a focus for their anger, it could be about anybody [but] he's choosing to be angry about something, which is nothing, but he's choosing to be angry all the time but, you know, has he got a choice in that? And why aren't the mental health services dealing with him?

\section{$[\ldots]$}

We can't meet his needs at all.

[V: Student employment advisor, abridged]

The exercise of power, in Foucauldian terms, creates intelligible subject positions that make it possible to 'name' or 'label' people in specific ways in particular circumstances. Here, the administrator is subject to bureaucratic power which positions her as an 'observing and classifying' subject who is able to name or classify other people (Foucault 1997; Mills 2004). Moreover, the student is also subject to power, albeit that which assembles him, simultaneously, as both a consumer of the administrative service and a 'resisting agent': he is neither subject to administrative power (he cannot be classified according to administrative criteria), yet nor does he make himself a subject of administrative power (for instance, by disclosing a disability classification, that he recognises of himself).

As this individual remains without a clear classification within the administrative environment, he represents a threat to order (Douglas 2002). To restore order, she attempts to assign him a classification that is available to her, selected from her administrative domain: he must be, she considers, either 'mentally ill' or having 'mental health needs'. Yet this attempted classification is also unsuccessful: as an administrator, she is not qualified to make this classification. Ultimately, he is labelled as anomalous because his "mental health needs", as she explains them, cannot be "met".

Critically, in this circumstance, both the administrator and student are folded into complex relations of power. For the administrator, her exercise of power enables her to invite a disability disclosure, to classify disability, to enable resources and create records. For the student, his power might include his capacity to make a disclosure, make demands of the 
Author Final Copy of Cox, N. (2017) 'Enacting disability policy through unseen support: the everyday use of disability classifications by university administrators' which was accepted for publication by the Journal of Education Policy on 03 Mar 2017. Deposited in concordance with sherpa.ac.uk/romeo/search.php?issn=0268$\underline{0939}$ guidelines. Publisher's final version is available at: $\underline{\text { http://dx.doi.org/10.1080/02680939.2017.1303750 }}$

administrators, to make choices, or indeed refuse a service. Both exercise in order to practice their work role or identity; their power provides the medium of social practice and is not something that is merely 'possessed' by them. These relations of power are complex: there is not a singular power that the administrator uses to 'oppress' the student, which he then 'resists'; both of them are simultaneously exercising power of different kinds.

The administrator, for instance, provides explanations that selected from medical and administrative discourses (“mentally ill”, "he's unemployable”). The student, conversely, makes selections chosen from other discourses (acting as a consumer and making choices about which service to receive, for instance). Both are positioned in a particular relationship to each other, although the power they can exercise is mismatched: drawing on medical language but not authority, the administrator exclaims, "Why aren't the mental health services dealing with him?" whilst, simultaneously, the student resists her attempts to subsume him into the administrative system. For the administrator, therefore, exercising power does not guarantee that 'something will happen' (Foucault 1990); it is this lack of guarantee that affords an opportunity for resistance or subversion to arise.

Conversely, another example shows how challenging situations might lead to reform. In this extract, the administrator explains the difficulties she and her (junior) peers experience when they feel obliged to offer a service (here, in respect of mental health) that they are unable or do not have the requisite expertise to offer. Yet, although 'counselling' services are, she explains, available for students to access, her team sometimes feel obliged (or are, through circumstances, required) to support individuals in the absence of support from other services that might, in her view, be more appropriate:

Y [But] how do [we] measure the impact that something like mental health is having on a student at any given time, and how expert are we at that? Not very...And I would actually say that I don't think that even mental health experts are very 'expert' at that! So, now we work very closely with counselling services and we're very clear... that there's a difference in our role to their role. Our role is very much about assessing the student with mental health issue[s] in light of what support they need for learning $[\ldots]$ 
Author Final Copy of Cox, N. (2017) 'Enacting disability policy through unseen support: the everyday use of disability classifications by university administrators' which was accepted for publication by the Journal of Education Policy on 03 Mar 2017. Deposited in concordance with sherpa.ac.uk/romeo/search.php?issn=0268$\underline{0939}$ guidelines. Publisher's final version is available at: $\underline{\text { http://dx.doi.org/10.1080/02680939.2017.1303750 }}$

But sometimes I have to say that we find [working with some students] difficult because the students themselves can be very challenging...We do have a number of students who are here at the moment who I think are genuinely far too ill to be here...

[Y: senior administrative manager, abridged]

Although she states that some students do not use her administrative service 'appropriately', and their wishes and demands can test the knowledge and skills her team, her depiction of certain expressions of mental disorder as 'challenging' appears, nonetheless, to have provided an opportunity for her to reflect upon and critically reconsider the policy, role and practice of administrators with regard to students disclosing of (mental health) disabilities and, moreover, the preparation and ongoing support for those staff for whom she is responsible.

In undertaking disability-related research that is 'critical', one commitment, as elaborated in this analysis, is to problematize the taken-for-granted ways in which disability is conceived through administrative work. Analyses of these data show, from a Foucauldian standpoint (Foucault 1997), how the exercise of power and knowledge is intrinsic to the 'naming' and classification of people in relation to disability within the administrative regime; correspondingly, analysis also shows the deleterious effect that errant classification or an administrative 'failure' to classify might also have upon a person: this subjectivising power is always imminent within policies where disability classification is prescribed.

\section{Discussion}

This paper now considers how disability classifications are upheld, how these classifications differentiate (and label) people, and how bureaucratic processes obscure the complex means through which people with disabilities become classified. Discussion then considers the agency of administrators as they broker and support the disclosure of disability, practices which also propagate the ideological imperatives of the university. Finally, the administrative classification of dyslexia and mental disabilities is considered, inviting discussion about the 'limits' of administrative classification, and for whom such limits may be harmful.

\subsection{Upholding disability classifications}

The analysis shows how administrators circulate expert-ascribed disability classifications (for instance, dyslexia) during their everyday work, and how they explain their actions in 
Author Final Copy of Cox, N. (2017) 'Enacting disability policy through unseen support: the everyday use of disability classifications by university administrators' which was accepted for publication by the Journal of Education Policy on 03 Mar 2017. Deposited in concordance with sherpa.ac.uk/romeo/search.php?issn=0268$\underline{0939}$ guidelines. Publisher's final version is available at: $\underline{\text { http://dx.doi.org/10.1080/02680939.2017.1303750 }}$

normative terms, for instance, to "prevent discrimination". These practices serve to instate a person with a disability through differentiation, classification and naming, a "constraint of conformity" (Foucault 1995, 183) that places the student with a disability in a liminal position with regard to non-disabled students (Turner 2008; Campbell 2008; Turner 2012). Their descriptions of students with disabilities are never incorporated fully within the realm of administrative-pedagogic normalcy, yet they are also never fully outside it; instead, people with disabilities remain subject to a perpetual, problematizing, administrative gaze.

It is the responsibility of (some) administrators to maintain a centralised database that contains information about the classifications of students' disabilities in administrative terms; this information corresponds with 'expert' (medical, psychological, pedagogic) designations of disability. Administrators therefore play a tacit role in maintaining what Foucault (1980) describes as an apparatus (dispositif) of control; this apparatus - the total 'sum' of organisational policy, procedure and labour - creates knowledge 'about' disability, assembles recognisable and 'acceptable types' of disabled subject, elicits individual information from them or 'about' them, then circulates the knowledge and practices that sustain their ongoing classification.

These findings reveal that the administrative practices that sanction students' disability classification do not require the administrator to explicitly possess or demonstrate medical, educational or psychological expertise with regard to disability. Although expert knowledge about disabilities is embedded within administrative practices (for instance, as terminology upon a 'checklist'), the knowledge that underpins this remains concealed (Douglas 1987). Expert power is discernible only in the moment of classification, for instance during students' enrolment; at other times, expert knowledge remains obscured behind policy and process.

In addition, analysis reveals how episodic and highly governed administrative interventions can have a palpable and enduring impact upon the student with a disability. Given that disclosure is 'invited' by the university - and often couched in terms of benefit and agential control - these findings accentuate the problematic 'pathways to disclosure' experienced by people, particularly those with mental health concerns. Barriers are erected in part due to the liminal (and precarious) administrative classification(s) people are assigned as part of the disclosure 'process', in part due to the 'lack of fit' of available supports, and perhaps, as Hughes, Corcoran, and Slee (2016) also show, due to misalignment between a person's stated 
Author Final Copy of Cox, N. (2017) 'Enacting disability policy through unseen support: the everyday use of disability classifications by university administrators' which was accepted for publication by the Journal of Education Policy on 03 Mar 2017. Deposited in concordance with sherpa.ac.uk/romeo/search.php?issn=0268$\underline{0939}$ guidelines. Publisher's final version is available at: $\underline{\text { http://dx.doi.org/10.1080/02680939.2017.1303750 }}$

needs, their expectations, and universities' ability to fulfil these.

\subsection{Supporting disability disclosure through administrative brokerage}

Through the exercise of medical (impairment-focused) and bureaucratic power, administrative practice produces the subjects and practices of exclusion - 'othering' - casting people as liminal, or even invisible to, the administrative regime (Foucault 1997; Mills 2004; Slee 2001). This may impede or disallow the disclosure of a disability: disclosure, already a series of complex personal experiences and encounters (Riddell and Weedon 2014), may be made more difficult due to the effort needed to 'redefine' oneself in order to align personal experiences with the expectations (and exclusions) of the administrative regime and its encultured disability knowledge(s) (Hughes, Corcoran, and Slee 2016).

Administratively, disability disclosure is not a single event, although within policy it may be framed as such; rather, as for the student, it is a process. The invitation to disclose relates to a number of circumstances, not least the legal duties impressed upon the university, as described earlier. As such, promoting and facilitating disclosure is an important administrative function. Disclosure of a disability by a student invites 'occasions for action' that oblige interpersonal work (for students and administrators) and helps them accomplish the ideological goals of the organisation (Pence 2001).

The actions of the administrator in the handling of student information in relation to individual disability represent 'scripts' that help administrators to broker a disability disclosure by the student. This script progresses students' assessment through a system of administrative actions. Both the administrator and the administrative script function concurrently: the 'acting out' of the script by the administrator (e.g. completing a checklist) is assisted by the utterance of 'disability-appropriate' language by the administrator. Therefore, to broker a disclosure, administrators must not only support a personal disclosure (practically and emotionally laborious for the student), but their brokerage must also articulate with institutional and legal demands. As such, the agency of administrators is critical.

In the study setting (UK), it is the student's responsibility and choice to disclose a disability. Administrators tacitly recognise disclosure as a choice through their 'discretion' in the disclosure and self-classification process; however, they also work to inaugurate and sustain disability classification by attempting to ensure that knowledge (data) about individual 
Author Final Copy of Cox, N. (2017) 'Enacting disability policy through unseen support: the everyday use of disability classifications by university administrators' which was accepted for publication by the Journal of Education Policy on 03 Mar 2017. Deposited in concordance with sherpa.ac.uk/romeo/search.php?issn=0268$\underline{0939}$ guidelines. Publisher's final version is available at: $\underline{\text { http://dx.doi.org/10.1080/02680939.2017.1303750 }}$

students is 'total', thereby maintaining a system of administrative surveillance which acts as a proxy for expert (e.g. medical or psychological) observation (see Rose 1998).

\subsection{Safe or repudiated classification: dyslexia and mental disability}

In what circumstances administrative surveillance is successful, and when it can no longer be sustained, is evidenced through analysis of the contrasting responses to dyslexia and mental disabilities. For administrators in this study, dyslexia had become a closely-scripted and 'cherished classification' (Douglas 2002) which functioned to make visible to the organisation particular 'kinds of people' who, if not identified early enough or with exactitude, might represent a risk to the organisation. Students with dyslexia symbolise what is at stake in the educational context: literacy, writing, comprehension, and the ability to organise oneself. The unequivocal ease in which the administrators are able to identify, normalize and regularise dyslexia indicates how firmly these expert knowledges are maintained and enforced through administrative and pedagogic practice.

The administrative response to dyslexia comprises a collection of normalizing practices that support the closing of the 'gap' between normalcy and disability. Administrative interventions (such as enacting reasonable adjustments), ameliorate an organisationalpedagogic risk, the "danger of being unable to learn" (Foucault 1995, 180). This risk becomes calculable through the administrators' application of their acquired expert or pedagogic knowledge about dyslexia. These knowledges permeate the administrative regime, serving to describe the corrective responses that are necessary for 'organisational order' and student achievement. For some students, the 'ease' by which dyslexia is administered, and the 'packaged' interventions that result, may be beneficial, although this experience is not explored here. However, the rationalized ways in which people disclosing dyslexia are administered might risk marginalizing students with more complex barriers to learning.

In contrast, the classification of mental health as a disability was troublesome to the administrators in this study, and in many ways signified a failure of the disability classification schema used by them in their everyday work. Administrators sometimes 'explained' their failure to classify a student disclosing a mental health issue in terms of the student's own psychological weaknesses (see Lawler 2014) and not, in contrast to dyslexia, as something 'nameable' and which could be subjected to meaningful intervention. 
Author Final Copy of Cox, N. (2017) 'Enacting disability policy through unseen support: the everyday use of disability classifications by university administrators' which was accepted for publication by the Journal of Education Policy on 03 Mar 2017. Deposited in concordance with sherpa.ac.uk/romeo/search.php?issn=0268$\underline{0939}$ guidelines. Publisher's final version is available at: $\underline{\text { http://dx.doi.org/10.1080/02680939.2017.1303750 }}$

Unlike dyslexia, which can be subjected to expert intervention (e.g. educational psychology), classified, and subjected to intervention (e.g. a prescribed package of support), for mental disabilities, the threat to administrative intervention is often ambiguity and the danger such ambiguity brings to policy accomplishment. Students with mental health concerns are sometimes depicted as being resistant to intervention via regular university 'disability processes', and attempts to ameliorate the danger of a 'failed classification' may be met by unqualified (lay) classification and questioning of the veracity of students' testimonies.

The disavowal of the voice and identity of people with mental disabilities represents an epistemic erasure and injustice and, arguably, is a feature of Westernised, bureaucratised systems which accord privilege to medical (and psychiatric) discourse (Cox and Webb 2015). The findings of this study show how discourses which describe mental wellness (or its perceived absence) have been (partly) borrowed from psychiatry and inserted into the bureaucratic and administrative apparatus of disability disclosure and its administration.

A Foucauldian standpoint on mental disabilities - in Foucault's parlance, 'madness' - rejects the claimed objectivity of medical science, instead arguing that classifying mental disability is a moral endeavour, albeit one glossed by a discourse of scientific truth (Foucault 1989). However, it might be naïve (and unfair) to confer blame wholly upon the professions: lay people, in everyday life - including universities - make moral judgements about people with mental disabilities, some of which become, over time, legitimized by experts in the form of classifications (Spandler, Anderson, and Sapey 2015, 17).

The findings of this study partly reflect this position: whilst disability classifications are partly created by the medical and psychological ('Psy') professions, they are inscribed, circulated and enacted within administrative and pedagogic discourse and practice, albeit not always successfully. The findings show that mental disabilities are ambiguous for the administrators as their presence may incite different explanations (and no singular 'truth'); similarly, however, 'mental disabilities' are also anomalous as, despite being assigned this prototype classification, they are understood not to be easily accommodated within established schemes of disability classification, 'expert' or otherwise. The analysis also showed how individuals who fall 'outside' the discursive limits of what 'can be named' as a disability in administrative contexts risk being labelled as 'dangerous', and might invite avoidance and 'explanation' in other ways (Douglas 2002). 
Author Final Copy of Cox, N. (2017) 'Enacting disability policy through unseen support: the everyday use of disability classifications by university administrators' which was accepted for publication by the Journal of Education Policy on 03 Mar 2017. Deposited in concordance with sherpa.ac.uk/romeo/search.php?issn=0268$\underline{0939}$ guidelines. Publisher's final version is available at: $\underline{\text { http://dx.doi.org/10.1080/02680939.2017.1303750 }}$

\section{Concluding remarks}

Disability-related policies invite classification of students and the overcoming of disabling barriers. Critically, however, disabling barriers are often articulated within policy at individual rather than organisational levels. As such, disability persists as an individual 'problem to be fixed', rather than an opportunity to reconceive what inclusion 'means' in higher education. Administrative systems accomplish 'support' for people with disabilities, but do so as part of an ideology that defines inclusive practice in terms of process, data/metrics, legal concordance and adjustments. Though concordant with this, administrators often provide an essential adjunct and use their agency to provide personalized interventions.

Notwithstanding inclusionary 'glossing' of policy, people with disabilities remain a threat to the epistemic and ideological order of administrative and pedagogic discourse and practice. Whilst legally concordant positive steps are being made in order not to render people with disabilities invisible, when people are rendered visible in policy, they are often done so as 'subjects of difference'. Therefore, whilst 'good work' is being done, this 'work' often remains locked into individual, medicalised conceptions of disability-as-difference.

Moreover, this individualistic approach responsibilizes students: framed as a 'choice', it remains the students' responsibility to activate and make meaningful their environment; although there are risks to the organisation, risks are also conferred upon students as they navigate the disclosure process. In this sense, whether disclosure is a 'choice' becomes a moot point as their personal achievement (and identity) is at stake.

In making a disclosure, students are individuated and 'marked out'. Yet, paradoxically, as Kerschbaum (2013 n.p.) notes, "acts of disaccomodation and prejudice are not attributed to human agents"; that is, whilst the process of becoming knowable as a person with a disability is individuated, the absence of adjustment or accommodation is framed as structural, perhaps inevitable. However, this paper shows that, despite concerns that disability and agency might be diametrically opposed (Kerschbaum 2013), the incorporation of disability work into the administrative realm presents a new opportunity for critical reconsideration of accommodations people might need in order to become fully included into higher education.

This said, critical concerns remain and should not be understated, not least regarding those that arise when the identities of people are inserted prescriptively into administrative systems. 
Author Final Copy of Cox, N. (2017) 'Enacting disability policy through unseen support: the everyday use of disability classifications by university administrators' which was accepted for publication by the Journal of Education Policy on 03 Mar 2017. Deposited in concordance with sherpa.ac.uk/romeo/search.php?issn=0268$\underline{0939}$ guidelines. Publisher's final version is available at: $\underline{\text { http://dx.doi.org/10.1080/02680939.2017.1303750 }}$

This is of particular importance for people who disclose mental health concerns: their liminality (and sometimes invisibility) to the administrative regime exposes the tension between a normative position (legally enshrined accommodations and rights for people with disabilities, emboldened by expert knowledge) and being 'marked-out' and described in terms of 'instability' and 'lack-of-fit'. As such, whilst increased recognition of the mental health needs of people entering university may be viewed as progressive, caution is nonetheless required: classification of people risks stripping people of their agency and their identity, with uncertain and sometimes deleterious outcomes.

Policies also necessarily navigate between academic demands and employability demands. This is particularly problematic for professional programmes of study (e.g. medicine, law, nursing, social work), where employability and public protection are at stake (Riddell and Weedon 2014). Policy-makers may need to reconsider how disclosure can be supported and accomplished, particularly where employability and industrial relations between University and industry are of increasing importance, such as in the UK.

Critically, in focusing upon disability disclosure and support as a process and constellation of resources, policy-makers risk significantly underestimating the agency asserted by nonspecialist administrative tasks as they work to offer a fair and inclusive service environment for students. The practice of such agency requires an environment in which the personal capital of administrators is cultivated and rewarded on a par with measurable 'productivity' and administrative outcomes/metrics.

\subsection{Implications for practice}

This study begins to reveal the tacit but nonetheless essential contribution that administrative staff make to the support of students disclosing disabilities in the higher education setting. The brokerage role played by administrators when supporting students with ostensibly routine activities shows how administrators require not only affective interpersonal skills, but also a nuanced grasp of the politicised and changeable lexicon that frames the disability experience. Therefore, the foregrounding of the contemporary disability experience within mandatory training and continuing professional development deserves consideration. Additionally, as they are often the first contact point for student-raised concerns, opportunities to develop the self-assurance of administrators who are servicing the needs 
Author Final Copy of Cox, N. (2017) 'Enacting disability policy through unseen support: the everyday use of disability classifications by university administrators' which was accepted for publication by the Journal of Education Policy on 03 Mar 2017. Deposited in concordance with sherpa.ac.uk/romeo/search.php?issn=0268$\underline{0939}$ guidelines. Publisher's final version is available at: $\underline{\mathrm{http}} \mathrm{://dx}$.doi.org/10.1080/02680939.2017.1303750

students experiencing mental health difficulties should be explored. Co-production of training activities together with people with disabilities (including current students) may help to embolden staff development, and maintain the currency and authenticity of training offered.

\subsection{Limitations to this study}

This research was undertaken within a single HE establishment in the UK, a sole researcher undertook the ethnographic fieldwork over a protracted period, and (as typical for this approach) took singular responsibility for interpretation and analysis of the dataset. The data included constitute a sub-set of the ethnographic data, and selection of data for inclusion was for analytic fitness and pragmatism, not completeness. Participants represent a purposive selection of individuals selected for their range and typicality of role, not sample size or with regard to conventional demographic indicators. As such, although no claims are made with regard to generalisability, cautious claims can be made about the transferability of findings to other HE settings in similar jurisdictions where participation of people with disabilities is paramount and where administrative workers play an essential role in the services delivery.

\section{Acknowledgements}

The author thanks the administrators of the host organisation for their support and participation in this research. Their true names are not provided in this report in order to protect other participants who chose to make anonymous contributions. This research received no specific grant from any funding agency in the public, commercial or not-for-profit sectors. 
Author Final Copy of Cox, N. (2017) 'Enacting disability policy through unseen support: the everyday use of disability classifications by university administrators' which was accepted for publication by the Journal of Education Policy on 03 Mar 2017. Deposited in concordance with sherpa.ac.uk/romeo/search.php?issn=0268$\underline{0939}$ guidelines. Publisher's final version is available at: $\underline{\text { http://dx.doi.org/10.1080/02680939.2017.1303750 }}$

\section{References}

Alvesson, Mats, and Kaj Sköldberg. 2009. Reflexive Methodology: New Vistas for Qualitative Research. 2nd ed. UK, London: Sage.

Barnes, Colin, and Geof Mercer. 2010. Exploring Disability: A Sociological Introduction. 2nd ed. Cambridge, UK; Malden, MA: Polity Press.

British Dyslexia Association. (n.d.). What are Specific Learning Difficulties? Accessed August 10, 2016, from http://www.bdadyslexia.org.uk/educator/what-are-specificlearning-difficulties

Browne, John, Michael Barber, Diane Coyle, David Eastwood, Julia King, Rajay Naik, and Peter Sands. 2010. Securing a Sustainable Future for Higher Education: An Independent Review of Higher Education funding and Student finance. United Kingdom: Department for Business, Innovation \& Skills.

Campbell, Fiona Kumari. 2005. "Legislating disability". In: Tremain, S. (ed.). Foucault and the government of disability. University of Michigan Press, 108-130.

Campbell, F. K. 2008. "Refusing Able(ness): A preliminary conversation about Ableism" M/C Journal of Media and Culture, 11(3). Retrieved February 12, 2017, from http://journal.media-culture.org.au/index.php/mcjournal/article/view/46

Corker, Mairian, and Tom Shakespeare. 2002. Disability/postmodernity: Embodying Disability Theory. London: Continuum.

Cox, Nigel and Webb, Lucy 2015. "Poles apart: does the export of mental health expertise from the Global North to the Global South represent a neutral relocation of knowledge and practice?" Sociology of Health \& Illness, 37(5), 683-697. https://doi.org/10.1111/1467-9566.12230

De Vault, Marjorie L., and Liza McCoy. 2006. “Institutional Ethnography: Using Interviews to Investigate Ruling Relations". In Institutional Ethnography as Practice, edited by D. E. Smith, 18-44. Oxford: Rowman and Littlefield. 
Author Final Copy of Cox, N. (2017) 'Enacting disability policy through unseen support: the everyday use of disability classifications by university administrators' which was accepted for publication by the Journal of Education Policy on 03 Mar 2017. Deposited in concordance with sherpa.ac.uk/romeo/search.php?issn=0268$\underline{0939}$ guidelines. Publisher's final version is available at: $\underline{\text { http://dx.doi.org/10.1080/02680939.2017.1303750 }}$

Dobson, Ian R. 2009. “The Journal of Higher Education Policy and Management: An Output Analysis". Journal of Higher Education Policy and Management 31 (1): 3.

Douglas, Mary. 1987. How Institutions Think. London: Routledge and Kegan Paul.

Douglas, Mary. 2002. Purity and Danger. Routledge Classics Edition. London: Routledge.

Elstad, Eyvind. 2008. “Towards a Theory of Mutual Dependency between School Administrators and Teachers". Educational Management Administration \& Leadership 36 (3): 393-414.

Foucault, Michel. 1980. Power/Knowledge. London: Pearson Education.

Foucault, Michel. (1989). Madness and Civilization: A history of Insanity in the Age of Reason. New York: Routledge.

Foucault, Michel. 1990. The History of Sexuality, Vol. 1: An introduction. London: Penguin Books.

Foucault, Michel. 1995. Discipline and Punish: The Birth of the Prison. New York: Routledge.

Foucault, Michel. 1997. “Technologies of the Self”. In Ethics: Subjectivity and Truth, edited by Paul Rabinow, 223-52. New York: New Press.

Goodley, Dan. 2016. Disability Studies: An Interdisciplinary Introduction. 2nd edition. Thousand Oaks, CA: Sage Ltd.

Hepple, B. A. 2014. Equality: The Legal Framework. Second edition. Oxford, United Kingdom: Hart Publishing.

Higher Education Funding Council for England. 2016. Supporting Disabled Students. Higher Education Funding Council for England. Accessed August 10, 2016, from http://www.hefce.ac.uk/sas/inequality/disabled/

Honig, Meredith I. 2009. "No Small Thing: School District Central Office Bureaucracies and the Implementation of New Small Autonomous Schools Initiatives". American Educational Research Journal 46 (2): 387-422. 
Author Final Copy of Cox, N. (2017) 'Enacting disability policy through unseen support: the everyday use of disability classifications by university administrators' which was accepted for publication by the Journal of Education Policy on 03 Mar 2017. Deposited in concordance with sherpa.ac.uk/romeo/search.php?issn=0268$\underline{0939}$ guidelines. Publisher's final version is available at: $\underline{\text { http://dx.doi.org/10.1080/02680939.2017.1303750 }}$

Hughes, B. 2004. "Disability and the Body". In Disabling Barriers, Enabling Environments, edited by J. Swain, 63-68. London: Sage.

Hughes, K., Corcoran, T., \& Slee, R. (2016). "Health-inclusive higher education: listening to students with disabilities or chronic illnesses". Higher Education Research \& Development, 35(3), 488-501. https://doi.org/10.1080/07294360.2015.1107885

Kerschbaum, Stephanie. 2013. "Disability and Linguistic Agency”. Profession (December 2013). Accessed October 24, 2016, from https://profession.mla.hcommons.org/2013/12/09/faculty-members-accommodationand-access-in-higher-education/

Kerschbaum, Stephanie L. 2014. Toward a New Rhetoric of Difference. CCCC Studies in Writing and Rhetoric. Urbana: Conference on College Composition and Communication, National Council of Teachers of English.

Lawler, Steph. 2014. Identity: Sociological Perspectives. 2nd Edition. Cambridge: Polity Press.

McElroy, James C., and Paula C. Morrow. 2010. "Employee Reactions to Office Redesign: A Naturally Occurring Quasi-Field Experiment in a Multi-Generational Setting”. Human Relations 63 (5): 609-36.

Macdonald, Stephen. J. 2009. Towards a sociology of dyslexia: exploring links between dyslexia, disability and social class. Saarbrüken: VDM Publishing House Ltd.

Mills, Sara. 2004. Discourse. 2nd Edition. UK, London: Routledge.

Pence, Ellen (2001). "Safety for battered women in a textually mediated legal system". Studies in Cultures, Organizations and Societies, 7 (2), 199-229

Riddell, Sheila, and Elisabet Weedon, 2014. "Disabled Students in Higher Education: Discourses of Disability and the Negotiation of Identity". International Journal of Educational Research, 63: 38-46. doi:10.1016/j.ijer.2013.02.008.

Rose, Nikolas. 1998. Inventing Our Selves: Psychology, Power, and Personhood. Cambridge: Cambridge University Press. 
Author Final Copy of Cox, N. (2017) 'Enacting disability policy through unseen support: the everyday use of disability classifications by university administrators' which was accepted for publication by the Journal of Education Policy on 03 Mar 2017. Deposited in concordance with sherpa.ac.uk/romeo/search.php?issn=0268$\underline{0939}$ guidelines. Publisher's final version is available at: $\underline{\text { http://dx.doi.org/10.1080/02680939.2017.1303750 }}$

Neil Selwyn, Michael Henderson \& Shu-Hua Chao (2016): "You need a system: exploring the role of data in the administration of university students and courses." Journal of Further and Higher Education, DOI: 10.1080/0309877X.2016.1206852

Sharrock, Geoff. 2000. "Why Students Are Not (Just) Customers (and Other Reflections on Life After George)". Journal of Higher Education Policy and Management 22 (2): 149.

Shildrick, Margrit. 2012. "Critical Disability Studies: Rethinking the Conventions for the Age of Postmodernity". In Routledge Handbook of Disability Studies, 30-41. New York: Routledge.

Slee, R. (2001). "Social justice and the changing directions in educational research: the case of inclusive education". International Journal of Inclusive Education, 5(2-3), 167177. https://doi.org/10.1080/13603110010035832

Smith, Dorothy. 2006. Institutional Ethnography as Practice. Maryland: Rowan and Littlefield.

Spradley, James P. 1979. The Ethnographic Interview. Bemont, CA: Wadsworth.

Spandler, H., Anderson, J., \& Sapey, B. (2015). Madness, distress, and the politics of disablement. UK, Bristol: Policy Press

Szekeres, Judy. 2004. “The Invisible Workers”. Journal of Higher Education Policy and Management 26 (1): 7-22. DOI: 10.1080/1360080042000182500.

Szekeres, Judy. 2006. "General Staff Experiences in the Corporate University”. Journal of Higher Education Policy and Management 28 (2): 133.

Szekeres, Judy. 2011. "Professional Staff Carve out a New Space”. Journal of Higher Education Policy and Management 33 (6): 679-91. doi:10.1080/1360080X.2011.621193.

Thurlow-Brenner, C. 2009. "Latina Administrators in Local Government: The Interplay of Role Orientation and Policy Intentions”. Administration \& Society 40 (8): 825-51. doi:10.1177/0095399708326346. 
Author Final Copy of Cox, N. (2017) 'Enacting disability policy through unseen support: the everyday use of disability classifications by university administrators' which was accepted for publication by the Journal of Education Policy on 03 Mar 2017. Deposited in concordance with sherpa.ac.uk/romeo/search.php?issn=0268$\underline{0939}$ guidelines. Publisher's final version is available at: $\underline{h t t p: / / d x . d o i . o r g / 10.1080 / 02680939.2017 .1303750 ~}$

Turner, Edith L. B. 2012. Communitas: The Anthropology of Collective Joy. 1 st ed. Contemporary Anthropology of Religion. New York: Palgrave Macmillan.

Turner, Victor. 2008. The Ritual Process: Structure and Anti-Structure. New Jersey: Transaction Publishers.

United Kingdom. 1995. Disability Discrimination Act.

United Kingdom. 2001. Special Educational Needs and Disability Act.

United Kingdom. 2005. Disability Discrimination Act.

United Kingdom. 2010. Equality Act.

Wengraf, Tom. 2001. Qualitative Research Interviewing. London: Sage.

Whitchurch, Celia. 2006. "Who Do They Think They Are? The Changing Identities of Professional Administrators and Managers in UK Higher Education”. Journal of Higher Education Policy and Management 28 (2): 159-71.

Whitchurch, Celia. 2008. "Beyond Administration and Management: Reconstructing the Identities of Professional Staff in UK Higher Education". Journal of Higher Education Policy and Management 30 (4): 375.

World Health Organization. 1992. The ICD-10 classification of mental and behavioural disorders: clinical descriptions and diagnostic guidelines. Geneva: World Health Organization.

Zimmermann, Jo An M., and Lawrence R. Allen. 2009. "Public Recreation Administration". Administration \& Society 41 (4): 470-502. 
Author Final Copy of Cox, N. (2017) 'Enacting disability policy through unseen support: the everyday use of disability classifications by university administrators' which was accepted for publication by the Journal of Education Policy on 03 Mar 2017. Deposited in concordance with sherpa.ac.uk/romeo/search.php?issn=0268$\underline{0939}$ guidelines. Publisher's final version is available at: $\underline{\text { http://dx.doi.org/10.1080/02680939.2017.1303750 }}$

Table 1. Participants whose data are included in this analysis

\begin{tabular}{|l|l|l|l|}
\hline Name & Gender & Time in service & Role \\
\hline S & M & 3 years & Junior administrator \\
\hline K & F & $>10$ years & Office manager \\
\hline $\mathbf{J}$ & F & 2 years & Junior administrator \\
\hline $\mathbf{Y}$ & F & $>10$ years & Senior administration manager \\
\hline A & M & 8 years & Faculty advisor on disability affairs \\
\hline V & F & $>10$ years & Student employment advisor \\
\hline
\end{tabular}

